\title{
Mode choice in access and egress stages of high-speed railway travelers in China
}

\author{
Haoran Yang (corresponding author) \\ East China Normal University \\ hryang@re.ecnu.edu.cn \\ Jianxi Feng (corresponding author) \\ Nanjing University \\ jxfup@nju.edu.cn
}

\author{
Martin Dijst \\ Luxembourg Institute of Socio-economic \\ Research \\ martin.dijst@liser.lu
}

Dick Ettema

Utrecht University

D.F.Ettema@uu.nl

\begin{abstract}
High-speed railway (HSR) has become a sustainable transport mode for inter-city travel, especially in China. As public transport (PT), the use of HSR involves access and egress to and from HSR stations. However, the literature focusing on the intra-city mode choice of HSR travelers is limited, especially regarding their differential socio-demographic and trip characteristics. This paper aims to fill that gap with an analysis of access/egress mode choice for business and leisure journeys in the Yangzi River Delta region. Using the HSR survey from Fudan University, we found that in China older and wealthier travelers have a strong preference for car use. For leisure travel, the explanatory power of the socio-demographic variables is much more influential in the egress than the access stage. With increasing access time, business travelers may be enticed to shift to a faster form of PT (e.g., subway rather than bus) in the access stage. With increasing line-haul time, only business travelers have a stronger preference for car use as their intra-city mode choice for business activities. A higher number of subway lines and diversity of land use around HSR stations is associated with less car use for business travelers in the egress stage.
\end{abstract}

Keywords: Access/egress stages, high-speed railway (HSR), China, mode choice

\section{Introduction}

The first European high-speed railway (HSR), the TGV Sud-Est between Paris and Lyon, was inaugurated in 1981 in France (Arduin \& Ni, 2005). Due to advantages of much higher speed than conventional railways, reduced traffic and congestion levels compared to private cars, and lower GHG emissions compared to airlines, HSR lines have been constructed and promoted as sustainable public transport (PT) connections for inter-city travel in other Western European countries, such as ICE in Germany and AVE in Spain (Givoni, 2006), and in China (Chen, 2012). As a PT mode, previously the HSR operation was mainly concerned with maintaining high frequency and limited stops to maintain the competitiveness of HSR travel at a high level. However, like any other PT mode, the use of

Copyright 2019 Haoran Yang, Martin Dijst, Jianxi Feng, \& Dick Ettema

http://dx.doi.org/10.5198/jtlu.2019.1420

ISSN: $1938-7849$ | Licensed under the Creative Commons Attribution - Noncommercial License 4.0

The Journal of Transport and Land Use is the official journal of the World Society for Transport and Land Use (WSTLUR) and is published and sponsored by the University of Minnesota Center for Transportation Studies.

\section{Article history:}

Received: June 21, 2018

Received in revised form:

June 2, 2019

Available online: September 27, 2019 
HSR involves access and egress to/from HSR stations. These stages are important elements of the whole HSR journey and can determine whether HSR line haul is an attractive transport mode for travelers compared to other transport modes (Krygsman, Dijst, \& Arentze, 2004; Brons, Givoni, \& Rietveld, 2009). Normally, the access/egress distances to newly built HSR stations are longer than for other PT terminals since newly built HSR stations are usually located in the periphery of (smaller) cities (Banister \& Givoni, 2013). This situation is much more severe in the context of China where HSR stations are located relatively far away from city centers (Chen \& Wei, 2013). Hence, improving the position of the HSR via improved intra-city trips to/from HSR stations is a core issue for the transition toward HSR sustainable mobility, especially in fast-urbanizing China.

In research, relatively less attention has been paid to the intra-city stages of trips to/from HSR stations, with a few exceptions. Tapiador, Burckhart, and Martí-Henneberg (2009) used aggregated interchange time and distance between stops of access/egress modes and HSR stations in European countries to identify the accessibility of HSR stations. Wang, Xu, and $\mathrm{He}$ (2013) focused on aggregated total travel time and quantified the time savings by the HSR trip regarding aggregated intra-city and inter-city stages of HSR trips, arguing that the accessibility of HSR stations determines the effectiveness of the HSR system in China. However, these studies all treated the aggregated travel times and distances of inter-city and intra-city as equal for all individuals, which underestimates the influence of differential socio-demographic characteristics and attributes on individual intra-city trips. For example, even when individuals face equal travel distances and the same accessibility of HSR stations from the same traffic analysis zones (TAZs), they may differ in their ability to use access mode choices to HSR stations based on their different socio-demographic characteristics, time budgets, and travel purposes. Thus, a move away from interest in aggregate research toward disaggregated individuals who generate the travel behavior is needed.

Some studies have examined the access/egress stages of local PT and conventional railways. For instance, studies on the influence of disaggregated socio-demographics and perceptions regarding the access/egress stages of trips to PT terminals such as conventional railway stations in the Netherlands (Krygsman et al., 2004; Givoni \& Rietveld, 2007; Brons et al., 2009) and metro stations in China (Yang, Zhao, Wang, Liu, \& Liu, 2015; Zhao \& Li, 2017) have been published. However, the socio-demographic characteristics of HSR travelers may differ from those using conventional PT given the nondaily long distance of HSR trips compared to daily local PT trips and the relatively high monetary but low time costs of HSR travel compared to the inter-city bus or conventional railway (Liu \& Kesteloot, 2015). Therefore, different impacts of trips and socio-demographic characteristics of HSR travelers may exist in their intra-city access and egress trips. In this paper, by focusing on the access/egress intra-city stages of HSR journeys in China from disaggregated socio-demographic information, travel motives, and travel times, the aim is to understand the differential impacts of HSR travelers' socio-demographics, trip and built-environment characteristics on the access/egress mode choices based on journey motive.

For our analysis, we use data from the 2014 HSR Travelers Survey in the Yangzi River Delta. We answer the research question in the following five sections. The second section starts with a review of relevant literature on the determinants of mode choice attributed to access and egress. Section 3 presents the research design and data set. Following is the empirically descriptive analysis of access and egress modes in Section 4. The regression models are discussed in Section 5. The sixth section offers the conclusions of our analysis. 


\section{Literature review of the determinants of mode choice for intra-city trips to HSR stations}

Existing research focuses on two types of mode choice, depending on whether it is combined with other transport modes. One is the unimodal transport mode from door-to-door without a combination of travel modes. The other is a multimodal mode choice including access/egress mode choice in association with other PT modes, such as trains and airlines (Zhao \& Li, 2017). By reviewing the existing literature, we identify three types of determinants related to the access/egress mode choice to/from PT terminals: trip characteristics, socio-demographics, and built-environment indicators. This review, based mainly on access/egress mode choices for conventional PT stations and partly on unimodal choice, is used to identify potential characteristics and determinants of mode choices in the access/egress stages of HSR journeys.

The trip characteristics are the most important explanatory variables for the access/egress mode choice in conventional PT. Among those characteristics, distance and travel time to the terminal are mentioned many times in the literature. In the Netherlands, for short travel distances $(3 \mathrm{~km})$ to conventional railway stations, travelers prefer to use active transport modes (walking and cycling) (Givoni \& Rietveld, 2007; Brons \& Rietveld, 2009). A study in the US revealed that more than 70\% of all access trips longer than $3.2 \mathrm{~km}$ to a transit station are made by car (Cervero, 2001). Although intuitive, the use of distance is somewhat simplistic since it is identical for all modes and fails to represent the characteristics of the trip accurately, namely, the relative time cost by mode. As Cervero (2002) mentioned, actual travel time is the most influential factor in the mode choice since travelers wish to limit total travel time regardless of the travel distance. Pels, NijKamp, and Rietveld (2003) also mentioned that the access time to airports is more important than any other variables in the access mode choice to airports. Martín, Román, García-Palomares, \& Guitiérrez, (2014) found that access and egress time to/from terminals are key factors in determining spatial competitiveness of transport modes for different travel purposes. Wen, Wang, and Fu (2012), however, found that the access mode choice of HSR travelers is less related to access time than monetary concerns in Taiwan. In addition to considering the access/egress travel time, actually, the line-haul time influences the time cost that travelers are willing to accept in the access and egress stages. Krygsman et al. (2004) found that people will accept a longer access time by cycling if their line-haul time is longer for their conventional railway trips in the context of the Netherlands. Therefore, the LOC (level of service) variables have various results in different contexts, which needs to be further explored in the context of China for HSR travelers.

Some studies have confirmed that travelers' socio-demographic characteristics are crucial determinants for the access/egress mode choice to conventional transport terminals. However, this literature is scarce. Most of the literature relates to determinants of the unimodal transport mode choice, which might apply to access/egress mode choice as well. Results have shown that, in comparison to men, females less often used the private car as the unimodal transport mode due to limited access to cars and consciousness of the high risk of driving (Kim \& Ulfarsson, 2008; Commins \& Nolan, 2011). Stronegger, Titze, and Oja (2010) found that men preferred cycling, while women preferred walking, as the unimodal transport mode because of women's perceived safety. Age also influences the access/egress mode choice. Zhao and $\mathrm{Li}$ (2017) found that when accessing metro stations, young people in China were less likely to cycle and more likely to use buses because younger generations in China rely on motorized transport more than older generations; Givoni and Rietveld (2007) found that young adults in the Netherlands used bicycles for access and egress to railway stations more frequently than older adults because of the better physical condition of young adults. Regarding income, when accessing metro stations, middle- and high-income earners in China were more likely to drive than cycle, whereas lowincome earners were more likely to take the bus (Zhao \& Li, 2017). The conclusions regarding the influ- 
ence of education differ. Researchers have found that travelers with a higher education preferred to use PT as the unimodal transport mode for medium and long travel distances (Limtanakool et al., 2006), while Dieleman, Dijst, and Burghouwt (2002) claimed that car use was more likely for travelers with a higher education in the Netherlands. However, research has also found contrasting results indicating that age, gender, and income were insignificant when estimating bicycle usage among rail transit users in the Netherlands (Krygsman et al., 2004) and China (Chen, Pel, Chen, Sparing, \& Hansen, 2012).

Furthermore, factors affecting mode choice decisions tend to vary by the purpose (Pan, Shen, $\&$ Zhang, 2009) because travelers face different space-time fixity and valuation of travel time when conducting activities. In general, business travel and commuting for obligatory activities are more fixed in time and place than leisure travel for discretionary activities (Wang, 2015). Algers (1993) found that in Sweden travelers with good employment status and economic well-being preferred to use a more expensive mode in getting to stations for business travel. The valuation of access time to the airport is higher for business than for leisure travelers because business travelers are more time-sensitive than leisure travelers (Pels et al., 2003).

The built environment at the macro and micro level largely influences passengers' travel behavior between origins to conventional rail transit stations and between destinations and conventional rail transit stations. On one hand, the built environment at the macro level refers to the urban form of city variables (Cervero, 2001; Krygsman et al., 2004). For instance, the location of conventional rail transit stations is also an important factor. Martens (2004) confirmed that when conventional railway stations are located in urban areas, conventional railway travelers are more likely to use the bus than the bicycle for medium and long access and egress distances. In addition, Martin and Shaheen (2014) found that subway travelers are likely to use the bicycle to access/egress metro stations in lower density suburban areas. Dobruszkes, Dehon, and Givoni (2014) found that location of HSR stations should be considered with regards to the precise departure and arrival points of upper social HSR travelers because the location of HSR stations influences their travel distance to/from stations. On the other hand, the built environment at the micro level refers to the transport infrastructure and diversity of mixed land use around PT station areas (Cervero \& Duncan, 2003; Krygsman et al., 2004; Zhao \& Li, 2017). A high level of PT service between origins and transit stations increases the chances of people using PT as the access mode (Zhao and $\mathrm{Li}$, 2017). Increasing the number of road intersections around origin areas diminishes the probability of car driving (Zhang, 2004; Sun, Ermagu, \& Dan, 2017). A high level of mixed land use around stations could play positive roles in encouraging active travel and PT to and from stations (Cervero \& Duncan, 2003; Zhang, 2016; Zhao \& Li, 2017).

Our review of the literature is based on conventional public transit stations rather than HSR stations. We argued in the introduction that socio-demographic and trip characteristics of HSR travelers might differ from those of conventional travelers. Specifically, we argued that the travel cost on inter-city multimodal HSR is higher and the volume of luggage is often greater than on conventional PT. Therefore, we first hypothesize that older and wealthier HSR travelers are more likely to choose a more expensive and convenient transport mode such as the car for their intra-city travel because of their declining physical condition and higher disposable income for transport. The second hypothesis is related to the time sensitivity of travelers. For example, business travelers, who are more sensitive to travel time costs (Shen, Chai, \& Kwan, 2015; Wang, 2015), would choose a travel mode being able to largely reduce the time needed for intra-city trips. Therefore, we expect that access/egress time and line-haul time of business travelers might have more implications for access/egress mode choices, resulting in a faster-speed access/egress transport mode compared to leisure travelers. Third, different from traditional PT terminals whose stations are normally located in urban areas where the majority of access/egress is active transport, most HSR stations in China are newly built and located in suburban areas with longer travel distances 
to the city center (Chen \& Wei, 2013). Therefore, we hypothesize that because the locations of HSR stations are far away from city centers, non-motorized transport modes might not be the major access/ egress mode choices in China. Fourth, intrinsic differences exist between the access and egress stage and between travelers with different space-time fixity. Travelers are more familiar with transport alternatives in the access stage than in the egress stage (Allard \& Moura, 2016) and obligatory travelers travel under more time-space constraints than discretionary travelers. Therefore, we hypothesize that the explanatory power of the socio-economic and trip characteristics and the built-environment attributes differ across travel stages and purposes.

\section{Research design}

We use survey data from Fudan University which were collected on June 6, 2014, with support from the Shanghai Railway Bureau. Due to the strict regulations of the Shanghai Railway Bureau, questionnaires had to be distributed to travelers in each carriage by train attendants rather than researchers for a single trip. Therefore, this survey could only reflect HSR travel behavior on a single day instead of a seasonality pattern. The survey was conducted on $G$ trains with an operational speed of $300 \mathrm{~km} / \mathrm{h}$ on two major HSR routes (Shanghai-Nanjing and Shanghai-Hangzhou) in the Yangzi River Delta; 741 of the total 1,000 questionnaires were valid (specifically, 160 from G7014 leaving Shanghai for Nanjing, 193 from G7141 leaving Nanjing for Shanghai, 193 from G7321 leaving Shanghai for Hangzhou, and 195 from G7326 leaving Hangzhou for Shanghai). The geographic distributions of the two routes are shown in Figure 1. Each route has nine HSR stations. The survey contains information on HSR travelers (e.g., gender, age, income level, educational level, occupational type) and journey information (e.g., journey purpose, departure and arrival stations, access/egress modes, times to/from HSR stations).

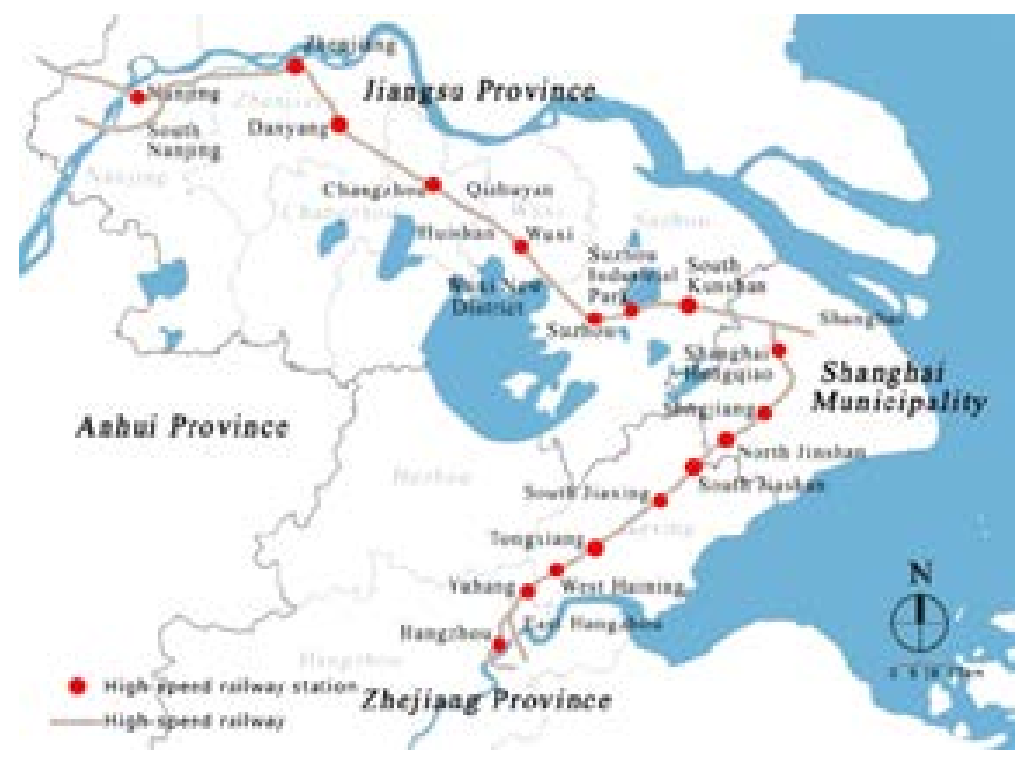

Figure 1. Locations of HSR stations in the Yangzi River Delta region 
Trip characteristics variables include journey purpose (i.e., business, family visit, tourism, commuting, other), access time, egress time, and line-haul time. Socio-demographic variables include gender, age, education level, and monthly income level. Built-environment variables include the location of HSR stations (urban or suburb areas) at the city level, diversity of mixed land use, number of subway lines, and number of road/street intersections within a $2 \mathrm{~km}$ radius around stations. The number of subway lines was determined based on a Baidu map to calculate the available subway lines within a 500m walking radius around stations and the number of road and street intersections is acquired by OpenStreetMap (OSM) to calculate the roads and streets specific for driving use within a $2 \mathrm{~km}$ radius of stations. Based on open points of interest (POI) data for Chinese cities in 2012, ${ }^{1}$ the diversity of mixed land use within a $\mathrm{km}$ radius around stations is calculated by following an entropy index:

$$
S=-\sum_{j} \frac{\left[P_{j k} \times \ln \left(P_{j k}\right)\right.}{\ln (j)}
$$

In this equation, $S$ refers to mixed land use (entropy), $j$ is the type of land use $(j=1,2, \ldots . j), K$ the stations of Shanghai-Nanjing and Shanghai-Hangzhou, and $P_{j k}$ the proportion of land use $j$ within a 2 $\mathrm{km}$ radius around stations. The entropy ranges from 0 (homogeneity-only, one type of land use) to 1 (heterogeneity-shares of uses evenly distributed over all land use categories). Previous research indicates that the built environment of both origin and destination in a single trip influences the mode choice of travelers. This means that not only the built environment around HSR stations but also the built environment of the origin in the access stage and the destination in the egress stage are important to understand travelers' intra-city mode choice. However, we only have the former information and the latter was not recorded in the survey, which could lead to some potential bias in model results. Except for three built-environment variables (number of subway lines, number of road/street intersections and entropy of mixed land use at a station level) and one trip characteristics variable (line-haul time) that are continuous variables, the location of HSR stations at a city level, the other trip characteristics, and socio-economic indicators are all categorical variables. Two categories of travel purposes (family travel and tourism travel) are incorporated into one category (leisure travel). Thus, ultimately, we categorized four trip purposes in our analysis: business, leisure, commuting, and other. The dependent variables in the analysis are the habitual access and egress mode choices to and from HSR stations; five categories are distinguished: subway, bus, car (driving alone or chauffeuring), walking and bicycle, and taxi or other.

For model selection, because both access and egress mode choices are categorical variables, we considered using the multinomial logit (MNL) model, which has typically been applied in studies to analyze the transport mode choice (Crockett \& Hounsell, 2005; Feng, Dijst, Wissink, \& Prillwitz, 2014). MNL can be used to predict the distribution probabilities or tendency toward different mode transport choices compared to one reference transport mode by considering different socio-demographics, trip characteristics, and built-environment factors. In addition, some passengers to and from stations without subway connections have a set of alternatives without a subway; therefore, an alternative-specific MNL model in Stata 13 is used for the regression analysis. It should be noticed that according to discrete

\footnotetext{
${ }^{1}$ Detailed information can be found from Liu \& Long, 2016.
} 
choice model theory (Ben-Akiva \& Lerman, 1985), LOC variables (travel cost and travel time) should be both considered in the model to control the interdependency between mode choice and travel time. However, travel cost for each alternative mode, which would be better to explain the impacts of LOC on mode choice, is not recorded in the survey. Therefore, we expect that MNL is more likely to reflect an association rather than direct causality. ${ }^{2}$ Moreover, there could be some endogeneity issues between socio-economic variables and travel time, ${ }^{3}$ by running the VIF test for those socio-economic variables and travel time, it could be found that the VIF values for them are all below 10, therefore, we assume the endogeneity issues are not strong enough in our cases.

\section{$4 \quad$ Descriptive analysis}

\subsection{Access stage}

In general, the subway is the major access mode choice, and the shares of walking/cycling and other transport modes are all together approximately $5.5 \%$. This is likely because the location of HSR stations in China is often far away from city centers (the mean value of the distance from city centers to departure stations is $8.87 \mathrm{~km}$ ). Thus, travelers cannot rely on non-motorized modes to access stations due to the long travel distance. Regarding travel purpose, commuters prefer to use the subway as a dominant access mode. For business travelers, next to the subway, the taxi also has a large share (27.5\%). In contrast, next to the subway, the bus has a large share of access mode (24.3\%) for leisure travelers.

In terms of gender, female travelers choose walking or cycling as access modes more than twice as often as male travelers. With increasing age, the share of subway as a dominant access mode decreases, while the share of car use increases, likely because of the physical convenience of this mode. There are also differences between education levels. Travelers with high education (undergraduate and graduate) prefer to use the subway as an access mode. With increasing education, the share of travelers using buses and taxis decreases. In addition, with increasing income, the share of bus use decreases and the share of the more expensive car and taxi increases.

With increasing access time, the share of PT use such as bus and subway increases, while the share of car and taxi use decreases. This shows that the shorter the access time, the faster the access mode travelers choose. This is different from conventional railway travelers in the Netherlands, who accept longer access times with a faster access mode (cycling instead of walking) (Krygsman et al., 2004). This might relate to findings in Taiwan that in general HSR travelers seem to be less time-sensitive to access mode so that for a longer access time they will accept a slower travel mode (Wen et al., 2012). As to the location of departure HSR stations, a higher share is associated with using the bus, car, and taxi but a lower share with the subway for travelers accessing stations in urban areas versus the suburbs.

\footnotetext{
${ }^{2}$ Obviously, the model only points out statistical correlations, meaning that the causality of the relationships is not as clear-cut as the model suggests. We have considered the use of structural equation models to explore the direction of causality in greater depth. However, handling complex categorical variables is cumbersome at best when estimating such models. In addition, the sample size of our data is too small to support these models.

3 Those socio-economic variables could affect both of travel time and mode choice, and some impacts on mode choice could be from the indirect impact via travel time.
} 
Table 1. Descriptive results of access stage

\begin{tabular}{|c|c|c|c|c|c|c|c|c|}
\hline & & Subway & Bus & Car & $\begin{array}{l}\text { Walking/ } \\
\text { Bicycle }\end{array}$ & Taxi & Others & $\begin{array}{l}\text { Total } \\
\text { cases }\end{array}$ \\
\hline Total share & 44.0 & 44.0 & 18.2 & 12.2 & 4.1 & 20.0 & 1.5 & 736 \\
\hline \multirow[t]{4}{*}{ Travel purpose } & Business & 41.6 & 12.5 & 14.7 & 2.5 & 27.5 & 1.3 & 320 \\
\hline & Leisure & 41.5 & 24.3 & 10.3 & 6.3 & 15.4 & 2.2 & 272 \\
\hline & Commuting & 52.8 & 19.4 & 11.1 & 4.6 & 11.1 & 0.9 & 108 \\
\hline & Other & 53.9 & 26.9 & 7.7 & 0.0 & 11.5 & 0.0 & 26 \\
\hline \multirow[t]{2}{*}{ Gender } & Male & 46.9 & 16.2 & 12.2 & 2.7 & 20.1 & 2.0 & 452 \\
\hline & Female & 39.8 & 21.9 & 11.5 & 6.5 & 19.7 & 0.7 & 279 \\
\hline \multirow[t]{3}{*}{ Age } & Young age $<30$ & 46.2 & 22.8 & 8.8 & 4.8 & 15.4 & 2.1 & 377 \\
\hline & Middle age $31-50$ & 43.2 & 12.7 & 15.6 & 2.2 & 25.4 & 1.0 & 315 \\
\hline & Old age $>50$ & 30.2 & 18.6 & 18.6 & 11.6 & 20.9 & 0.0 & 43 \\
\hline \multirow[t]{3}{*}{ Educational level } & $\begin{array}{l}\text { High school or } \\
\text { lower }\end{array}$ & 34.6 & 24.6 & 13.0 & 4.3 & 20.9 & 2.7 & 301 \\
\hline & Undergraduate & 50.9 & 14.2 & 10.8 & 3.4 & 19.8 & 0.9 & 324 \\
\hline & Graduate & 49.1 & 12.7 & 14.6 & 5.5 & 18.2 & 0.0 & 110 \\
\hline \multirow[t]{3}{*}{ Monthly income } & $<750$ euro & 40.8 & 26.6 & 9.9 & 4.9 & 15.9 & 1.9 & 365 \\
\hline & $750-1250$ euro & 47.3 & 11.5 & 14.9 & 2.7 & 22.3 & 1.4 & 148 \\
\hline & $>1250$ euro & 47.2 & 7.1 & 15.2 & 3.6 & 25.9 & 1.0 & 197 \\
\hline \multirow[t]{3}{*}{ Access time to stations } & $<30$ minutes & 39.2 & 15.7 & 15.4 & 4.2 & 22.7 & 2.8 & 286 \\
\hline & $31-60$ minutes & 47.9 & 19.3 & 11.4 & 1.8 & 19.6 & 0.0 & 326 \\
\hline & $>60$ minutes & 47.1 & 21.9 & 7.6 & 9.2 & 11.8 & 2.5 & 119 \\
\hline \multirow{3}{*}{$\begin{array}{l}\text { Location of HSR } \\
\text { stations }\end{array}$} & Center & 41.6 & 19.5 & 12.9 & 3.8 & 20.4 & 1.9 & 534 \\
\hline & Suburb & 51.0 & 14.8 & 10.7 & 5.1 & 17.9 & 0.5 & 196 \\
\hline & Mean & SD & & Min & $\operatorname{Max}$ & & & \\
\hline No. subway lines & 1.7 & 0.74 & & 0 & 3 & & & \\
\hline $\begin{array}{l}\text { No. road/street inter- } \\
\text { sections for driving }\end{array}$ & 400 & 133 & & 34 & 654 & & & \\
\hline $\begin{array}{l}\text { Entropy of mixed land } \\
\text { use }\end{array}$ & 0.53 & 0.14 & & 0.2 & 0.7 & & & \\
\hline
\end{tabular}

\subsection{Egress stage}

In general, the subway is the major egress mode choice and the share of walking/cycling and other in the egress stage is as low as in the access stage (the distance from city centers to the arrival station is 10.1 $\mathrm{km}$ ). Here, we only mention the remarkable differences compared to the access stage. Concerning travel purpose, different from the access stage, business travelers prefer the taxi to the subway while leisure travelers prefer the taxi to the bus. Regarding education level, with increasing education, the share of subway use as an egress mode increases. As to the station in the city center, different from the access stage, there is a lower share of bus and car use but a higher share of taxi use for travelers egressing stations in urban 
areas versus the suburbs.

A comparison between the access and egress stage with Table 1 divided by Table 2 is shown in Table 3 , which further explains the asymmetry between the two stages. It can be found that subway and car are more used in the access stage, while taxi in the egress stage. This reflects that taxi as a less difficult use for travelers compared to other modes is more likely to be chosen in the unfamiliar egress stage.

Table 2. Descriptive results of egress stage

\begin{tabular}{|c|c|c|c|c|c|c|c|c|}
\hline & & Subway & Bus & Car & $\begin{array}{l}\text { Walking/ } \\
\text { Bicycle }\end{array}$ & Taxi & Others & $\begin{array}{l}\text { Total } \\
\text { cases }\end{array}$ \\
\hline Total share & & 33.0 & 28.6 & 9.5 & 3.9 & 32.4 & 2.0 & 736 \\
\hline \multirow{4}{*}{ Travel purpose } & Business & 33.0 & 12.2 & 9.4 & 2.8 & 40.5 & 2.2 & 321 \\
\hline & Leisure & 30.2 & 24.6 & 8.8 & 4.8 & 29.0 & 2.6 & 272 \\
\hline & Commuting & 37.0 & 24.1 & 13.9 & 6.5 & 16.7 & 1.9 & 108 \\
\hline & Other & 38.5 & 19.2 & 3.9 & 0.0 & 34.6 & 3.9 & 26 \\
\hline \multirow[t]{2}{*}{ Gender } & Male & 33.6 & 18.8 & 9.1 & 3.5 & 32.7 & 2.2 & 452 \\
\hline & Female & 32.5 & 18.6 & 10.0 & 4.6 & 31.8 & 2.5 & 280 \\
\hline \multirow[t]{3}{*}{ Age } & Young age $<30$ & 32.0 & 24.3 & 7.9 & 4.5 & 28.3 & 2.9 & 378 \\
\hline & Middle age 31-50 & 34.9 & 12.1 & 10.8 & 2.9 & 37.8 & 1.6 & 315 \\
\hline & Old age $>50$ & 32.6 & 14.0 & 14.0 & 7.0 & 30.2 & 2.3 & 43 \\
\hline \multirow[t]{3}{*}{ Educational level } & $\begin{array}{l}\text { High school or } \\
\text { lower }\end{array}$ & 30.8 & 25.2 & 9.6 & 3.6 & 27.5 & 3.3 & 302 \\
\hline & Undergraduate & 32.1 & 14.8 & 10.2 & 3.7 & 37.0 & 2.2 & 324 \\
\hline & Graduate & 43.6 & 11.8 & 7.3 & 5.5 & 31.8 & 0.0 & 110 \\
\hline \multirow[t]{3}{*}{ Monthly income } & $<750$ euro & 33.1 & 27.3 & 6.8 & 4.6 & 26.5 & 1.6 & 366 \\
\hline & $750-1250$ euro & 37.4 & 12.2 & 10.2 & 2.0 & 33.3 & 4.8 & 147 \\
\hline & $>1250$ euro & 31.8 & 6.1 & 14.1 & 3.5 & 42.9 & 1.5 & 198 \\
\hline \multirow{3}{*}{$\begin{array}{l}\text { Egress time from } \\
\text { stations }\end{array}$} & $<30$ minutes & 28.9 & 16.7 & 12.1 & 6.3 & 34.3 & 1.7 & 239 \\
\hline & $31-60$ minutes & 36.6 & 18.0 & 9.4 & 1.4 & 31.6 & 3.1 & 361 \\
\hline & $>60$ minutes & 32.6 & 24.8 & 5.4 & 4.7 & 31.0 & 1.6 & 129 \\
\hline \multirow{3}{*}{$\begin{array}{l}\text { Location of HSR } \\
\text { stations }\end{array}$} & Center & 31.2 & 18.1 & 9.3 & 4.1 & 35.5 & 1.9 & 420 \\
\hline & Suburb & 36.5 & 19.0 & 10.0 & 3.9 & 27.7 & 2.9 & 310 \\
\hline & Mean & SD & & Min & $\operatorname{Max}$ & & & \\
\hline No. subway lines & 1.3 & 0.72 & & 0 & 2 & & & \\
\hline $\begin{array}{l}\text { No. } \mathrm{road} / \text { street inter- } \\
\text { sections for driving }\end{array}$ & 334 & 116 & 17 & 488 & & & & \\
\hline $\begin{array}{l}\text { Entropy of mixed land } \\
\text { use }\end{array}$ & 0.52 & 0.12 & 0.2 & 0.7 & & & & \\
\hline
\end{tabular}


Table 3. Asymmetry comparison between the access and egress stage

\begin{tabular}{|c|c|c|c|c|c|c|c|}
\hline & & Subway & Bus & Car & $\begin{array}{l}\text { Walking/ } \\
\text { Bicycle }\end{array}$ & Taxi & Others \\
\hline Total share & & 1.3 & 0.6 & 1.3 & 1.1 & 0.6 & 0.8 \\
\hline \multirow[t]{5}{*}{ Travel purpose } & Business & 1.3 & 1.0 & 1.6 & 0.9 & 0.7 & 0.6 \\
\hline & Leisure & 1.4 & 1.0 & 1.2 & 1.3 & 0.5 & 0.8 \\
\hline & Commuting & 1.4 & 0.8 & 0.8 & 0.7 & 0.7 & 0.5 \\
\hline & Other & 1.4 & 1.4 & 2.0 & & 0.3 & 0.0 \\
\hline & & & & & $*$ & & \\
\hline \multirow[t]{2}{*}{ Gender } & Male & 1.4 & 0.9 & 1.3 & 0.8 & 0.6 & 0.9 \\
\hline & Female & 1.2 & 1.2 & 1.2 & 1.4 & 0.6 & 0.3 \\
\hline \multirow[t]{3}{*}{ Age } & Young age $<30$ & 1.4 & 0.9 & 1.1 & 1.1 & 0.5 & 0.7 \\
\hline & Middle age 31-50 & 1.2 & 1.0 & 1.4 & 0.8 & 0.7 & 0.6 \\
\hline & Old age $>50$ & 0.9 & 1.3 & 1.3 & 1.7 & 0.7 & 0.0 \\
\hline \multirow[t]{4}{*}{ Educational level } & High school or & 1.1 & 1.0 & 1.4 & 1.2 & 0.8 & 0.8 \\
\hline & lower & & & & & & \\
\hline & Undergraduate & 1.6 & 1.0 & 1.1 & 0.9 & 0.5 & 0.4 \\
\hline & Graduate & 1.1 & 1.1 & 2.0 & 1.0 & 0.6 & $*$ \\
\hline \multirow[t]{3}{*}{ Monthly income } & $<750$ euro & 1.2 & 1.0 & 1.5 & 1.1 & 0.6 & 1.2 \\
\hline & $750-1250$ euro & 1.3 & 0.9 & 1.5 & 1.4 & 0.7 & 0.3 \\
\hline & $>1250$ euro & 1.5 & 1.2 & 1.1 & 1.0 & 0.6 & 0.7 \\
\hline \multirow[t]{3}{*}{ Intra-city travel time } & $<30$ minutes & 1.4 & 0.9 & 1.3 & 0.7 & 0.7 & 1.6 \\
\hline & $31-60$ minutes & 1.3 & 1.1 & 1.2 & 1.3 & 0.6 & 0.0 \\
\hline & $>60$ minutes & 1.4 & 0.9 & 1.4 & 2.0 & 0.4 & 1.6 \\
\hline \multirow[t]{3}{*}{ Location of HSR stations } & Center & 1.3 & 1.1 & 1.4 & 0.9 & 0.6 & 1.0 \\
\hline & Suburb & 1.4 & 0.8 & 1.1 & 1.3 & 0.6 & 0.2 \\
\hline & Mean & SD & Min & $\operatorname{Max}$ & & & \\
\hline No. subway lines & 1.3 & 1.1 & * & 1.5 & & & \\
\hline $\begin{array}{l}\text { No. } \mathrm{road} / \mathrm{street} \text { intersections for } \\
\text { driving }\end{array}$ & 1.2 & 1.1 & 2.0 & 1.3 & & & \\
\hline Entropy of mixed land use & 1.0 & 1.2 & 1.0 & 1.0 & & & \\
\hline
\end{tabular}

*The original value in both the access and egress stage is 0 .

\section{$5 \quad$ Access and egress mode choice models}

The travel mode categories of walking/cycling and other are not included in the multivariate analysis since they are not the major transport modes travelers choose to access and egress stations and the sample size of them is too small to run an alternative-specific MNL model. Thus, only four categories are used in the multivariate analysis (i.e., subway, bus, taxi, and car) where the car serves as the reference category 
in the multinomial logit model. Commuting and other travel purposes are not included in the MNL regression since the sample size is too small. For each of the journey purposes (business and leisure), two final models are presented in Tables 3 and 4, respectively.

Table 4. Access stage

\begin{tabular}{|c|c|c|c|c|c|c|c|c|c|c|c|c|}
\hline & \multicolumn{6}{|c|}{ Business } & \multicolumn{6}{|c|}{ Leisure } \\
\hline & \multicolumn{2}{|l|}{ Subway } & \multicolumn{2}{|l|}{ Bus } & \multicolumn{2}{|l|}{ Taxi } & \multicolumn{2}{|l|}{ Subway } & \multicolumn{2}{|l|}{ Bus } & \multicolumn{2}{|l|}{ Taxi } \\
\hline & B & OR & B & OR & B & OR & B & OR & B & OR & B & OR \\
\hline \multicolumn{13}{|l|}{ Gender $($ Male $=$ ref. $)$} \\
\hline Female & -0.594 & 0.552 & -0.231 & 0.794 & -0.247 & 0.781 & 0.296 & 1.344 & 0.233 & 1.263 & 0.365 & 1.441 \\
\hline \multicolumn{13}{|l|}{ Age (Young age $<30$} \\
\hline \multicolumn{13}{|l|}{$=$ ref.) } \\
\hline Middle age 31-50 & $-0.737^{*}$ & 0.479 & -0.311 & 0.733 & 0.0958 & 1.100 & -0.180 & 0.835 & -0.340 & 0.712 & -0.303 & 0.738 \\
\hline Old age $>50$ & $-2.273^{* * *}$ & 0.103 & 0.0579 & 1.060 & -0.101 & 0.904 & -0.271 & 0.763 & -0.370 & 0.691 & -1.609 & 0.200 \\
\hline \multicolumn{13}{|l|}{ Educational level } \\
\hline \multicolumn{13}{|l|}{ (High school or lower } \\
\hline \multicolumn{13}{|l|}{ ref.) } \\
\hline Undergraduate & 0.729 & 2.072 & 0.317 & 1.373 & -0.0222 & 0.978 & 0.0512 & 1.053 & -0.407 & 0.666 & -0.642 & 0.526 \\
\hline Graduate & 0.190 & 1.209 & 0.681 & 1.976 & -0.216 & 0.805 & -0.373 & 0.689 & -0.265 & 0.767 & -1.197 & 0.302 \\
\hline \multicolumn{13}{|l|}{ Monthly income } \\
\hline \multicolumn{13}{|l|}{$(<750$ Euro = ref. $)$} \\
\hline 750-1250 Euro & -0.109 & 0.896 & $-1.528^{* *}$ & 0.217 & 0.366 & 1.443 & 0.665 & 1.944 & 0.436 & 1.546 & 0.530 & 1.699 \\
\hline$>1250$ Euro & -0.267 & 0.766 & $-2.013^{* * *}$ & 0.134 & 0.0208 & 1.021 & -0.134 & 0.875 & -0.764 & 0.466 & 0.834 & 2.303 \\
\hline \multicolumn{13}{|l|}{ Access time $(<30$} \\
\hline \multicolumn{13}{|l|}{ minutes = ref.) } \\
\hline 31-60 minutes & 0.225 & 1.252 & 0.478 & 1.613 & -0.178 & 0.837 & 0.768 & 2.156 & 0.753 & 2.124 & 0.411 & 1.509 \\
\hline$>60$ minutes & $1.078^{*}$ & 2.938 & 0.00201 & 1.002 & -0.632 & 0.532 & 0.676 & 1.966 & $1.492^{* *}$ & 4.448 & 0.220 & 1.247 \\
\hline Line haul time & 0.265 & 1.303 & -0.995 & 0.370 & -0.368 & 0.692 & 0.740 & 2.095 & 0.221 & 1.247 & 1.050 & 2.857 \\
\hline \multicolumn{13}{|l|}{ Location of stations } \\
\hline \multicolumn{13}{|l|}{ (Suburb = ref.) } \\
\hline Urban & -1.297 & 0.273 & $2.473^{* *}$ & 0.0844 & -0.671 & 0.511 & -1.972 & 0.139 & 0.477 & 1.612 & 0.704 & 2.021 \\
\hline Land use entropy & -3.474 & 0.0310 & -6.180 & 0.00207 & -2.296 & 0.101 & -2.605 & 0.0739 & 2.699 & 14.87 & 5.145 & 171.6 \\
\hline No. subway lines & -0.416 & 0.660 & $-1.068^{* *}$ & 0.344 & -0.425 & 0.653 & -0.291 & 0.747 & -0.360 & 0.698 & 0.00593 & 1.006 \\
\hline $\begin{array}{l}\text { No. } \mathrm{road} / \text { street inter- } \\
\text { sections for driving }\end{array}$ & 0.523 & 1.686 & $0.932^{*}$ & 2.538 & 0.170 & 1.185 & 0.356 & 1.427 & -0.316 & 0.729 & -0.642 & 0.526 \\
\hline Constant & 2.363 & & $4.648^{* *}$ & & $2.900^{*}$ & & 2.003 & & 0.331 & & -1.493 & \\
\hline Observations & 1148 & & & & & & 931 & & & & & \\
\hline Cases & 290 & & & & & & 236 & & & & & \\
\hline Chi-square & 89.25 & & & & & & 50.41 & & & & & \\
\hline McFadden's R2 & 0.170 & & & & & & 0.164 & & & & & \\
\hline Nagelkerke R2 & 0.392 & & & & & & 0.388 & & & & & \\
\hline
\end{tabular}

${ }^{*} \mathrm{p}<.1^{* *} \mathrm{p}<0.05^{* * *} \mathrm{p}<0.01 "$ car as reference 
Table 5. Egress stage

\begin{tabular}{|c|c|c|c|c|c|c|c|c|c|c|c|c|}
\hline & \multicolumn{6}{|c|}{ Business } & \multicolumn{6}{|c|}{ Leisure } \\
\hline & \multicolumn{2}{|l|}{ Subway } & \multicolumn{2}{|l|}{ Bus } & \multicolumn{2}{|l|}{ Taxi } & \multicolumn{2}{|l|}{ Subway } & \multicolumn{2}{|l|}{ Bus } & \multicolumn{2}{|l|}{ Taxi } \\
\hline & B & OR & B & OR & B & OR & B & OR & B & OR & B & OR \\
\hline \multicolumn{13}{|l|}{ Gender $($ Male=ref. $)$} \\
\hline Female & -0.179 & 0.836 & -0.945 & 0.389 & 0.00440 & 1.004 & -0.109 & 0.897 & -0.286 & 0.751 & 0.0612 & 1.063 \\
\hline \multicolumn{13}{|l|}{ Age (Young age $<30$} \\
\hline \multicolumn{13}{|l|}{$=$ ref.) } \\
\hline Middle age $31-50$ & 0.690 & 1.994 & 0.405 & 1.500 & 0.546 & 1.726 & -0.365 & 0.694 & -0.559 & 0.572 & 0.0892 & 1.093 \\
\hline Old age $>50$ & 1.441 & 4.227 & -0.465 & 0.628 & 0.128 & 1.136 & $-2.019^{* *}$ & 0.133 & $-1.840^{* *}$ & 0.159 & -0.824 & 0.439 \\
\hline \multicolumn{13}{|l|}{ Educational } \\
\hline \multicolumn{13}{|l|}{ level (High school or } \\
\hline \multicolumn{13}{|l|}{ lower =ref.) } \\
\hline Undergraduate & 0.591 & 1.805 & -0.371 & 0.690 & 0.344 & 1.410 & -0.310 & 0.734 & -0.912 & 0.402 & -0.243 & 0.784 \\
\hline Graduate & 0.337 & 1.401 & 0.515 & 1.674 & 0.178 & 1.195 & $1.646^{*}$ & 5.184 & 0.0912 & 1.096 & 0.604 & 1.829 \\
\hline \multicolumn{13}{|l|}{ Monthly income } \\
\hline \multicolumn{13}{|l|}{$(<750$ Euro = ref. $)$} \\
\hline 750-1250 Euro & $-1.005^{*}$ & 0.366 & $-1.227^{*}$ & 0.293 & -0.281 & 0.755 & 0.165 & 1.179 & -0.379 & 0.685 & -0.115 & 0.891 \\
\hline$>1250$ Euro & $-1.436^{* *}$ & 0.238 & $-3.016^{* * *}$ & 0.0490 & -0.977 & 0.376 & $-2.292^{* * *}$ & 0.101 & $-2.951^{* * *}$ & 0.0523 & -0.840 & 0.432 \\
\hline \multicolumn{13}{|l|}{ Egress time $(<30$} \\
\hline \multicolumn{13}{|l|}{ minutes = ref.) } \\
\hline 31-60 minutes & 0.00369 & 1.004 & -0.562 & 0.570 & -0.464 & 0.629 & 0.458 & 1.581 & 0.509 & 1.663 & 0.642 & 1.900 \\
\hline$>60$ minutes & 0.984 & 2.675 & 1.369 & 3.932 & 0.957 & 2.605 & 0.666 & 1.946 & 0.625 & 1.868 & 0.335 & 1.397 \\
\hline Line haul time & -0.831 & 0.436 & $-1.793^{* *}$ & 0.166 & -0.584 & 0.558 & 0.0792 & 1.082 & 0.639 & 1.894 & 0.373 & 1.452 \\
\hline \multirow{2}{*}{\multicolumn{13}{|c|}{$\begin{array}{l}\text { Location of stations } \\
(\text { Urban = ref. })\end{array}$}} \\
\hline & & & & & & & & & & & & \\
\hline Suburb & 2.142 & 8.519 & -0.651 & 0.522 & 0.291 & 1.338 & 0.677 & 1.967 & 0.909 & 2.483 & 0.753 & 2.124 \\
\hline Land use entropy & 11.24 & 76142.4 & 2.854 & 17.36 & 1.577 & 4.840 & 2.889 & 17.98 & $4.745^{*}$ & 115.0 & 0.410 & 1.507 \\
\hline No. subway lines & $6.037^{* *}$ & 418.8 & -0.255 & 0.775 & 0.227 & 1.254 & 0.592 & 1.807 & -0.105 & 0.901 & -0.241 & 0.786 \\
\hline $\begin{array}{l}\text { No. road/street inter- } \\
\text { sections for driving }\end{array}$ & $2.249^{* * *}$ & 9.478 & 0.350 & 1.419 & 0.0770 & 1.080 & -0.196 & 0.822 & $-0.761^{*}$ & 0.467 & -0.00808 & 0.992 \\
\hline Constant & $-22.67^{* *}$ & & 1.551 & & 0.774 & & -0.475 & & 0.964 & & 0.453 & \\
\hline Observations & 1148 & & & & & & 931 & & & & & \\
\hline Cases & 290 & & & & & & 236 & & & & & \\
\hline Chi-square & 63.63 & & & & & & 72.10 & & & & & \\
\hline McFadden's R2 & 0.172 & & & & & & 0.138 & & & & & \\
\hline Nagelkerke R2 & 0.398 & & & & & & 0.334 & & & & & \\
\hline
\end{tabular}

${ }^{*} \mathrm{p}<.1{ }^{* *} \mathrm{p}<0.05^{* * *} \mathrm{p}<0.01$ " car as reference 


\subsection{Business travel}

\subsubsection{Access stage}

Among the socio-demographic variables, age and monthly income have a significant influence on the access mode choice. Older business travelers show an increased propensity to use the car rather than the subway. The results seem to support the conclusion from Europe and the US that among seniors, PT is not a popular travel mode for intra-city trips (Schwanen, Dijst, \& Dieleman, 2001), but they contradict the conclusion from China that elderly people are more likely to travel by PT than by private car in the city of Nanjing (Feng, 2017). This finding might be related to the differences in the composition of the elderly groups in our research. Older HSR business travelers in China are normally senior staff members who have chauffeuring services for their non-recurrent HSR non-daily travel versus normal elderly people who have retired. Furthermore, higher income business travelers are characterized by less use of buses than cars because of the higher monetary cost associated with car use.

Compared to business travelers with access time shorter than 30 minutes, those with access time longer than 60 minutes are less likely to choose the car. As mentioned earlier, HSR travelers will accept a slower travel mode for longer access time because of being less sensitive to access time than monetary cost (Wen et al., 2012). However, according to discrete choice model theory (Ben-Akiva \& Lerman, 1985), it is important to note that our analysis reflects associations between access time and travel mode choice rather than clear causal relationships between them. The causality might also be the other way around, which means that given a certain access distance, the increase in subway use instead of car use may allow for a longer access time. Furthermore, when line-haul time is extended, the probability of using the car increases. This might relate to the time-space constraints imposed on inter-city HSR travelers who are willing to control the total travel time (access + line haul + egress) (Krygsman et al., 2004). A longer line-haul time means business travelers are less inclined to accept longer intra-city travel time to save total travel time. Also, the high time costs of intra-city trips may limit the acceptability of low-speed PT modes in cities, especially for business travel (Scheiner, 2010a). In China, taking a bus without an exclusive right-of-way is rather slow on routes with high traffic volumes (Pan et al., 2009). Thus, with increasing line-haul time, travelers will likely prefer the fastest mode, car driving, in the access stage.

Compared to socio-economic and trip characteristics, built-environment variables show significant impacts on mode choice in the access stage for business travelers. The location of HSR stations seems to be an important factor since business travelers show a high propensity to use the car rather than the bus to reach HSR stations in suburb areas. Moreover, with the increasing number of subway lines around the departure stations, business travelers' propensity for using the car increases compared to the bus. Both factors reflect a typical situation in China that normally newly built HSR stations in the suburb areas with a low number of population density have a rather low provision of the bus instead of the subway from centers (Wang et al., 2013). Therefore, business travelers who are more sensitive to time cost tend to choose the car instead of the bus to access newly built HSR stations in the less crowded suburb areas. Moreover, with the increasing number of road intersections for driving around departure stations, business travelers prefer to use the bus instead of the car to access stations. This might be related to the fact that there is usually less car traffic in areas with more intersections and an improvement in street network connectivity by increasing the number of interactions can increase bus ridership (Zhang, 2016; Feng, 2017).

\subsubsection{Egress stage}

Of the socio-demographic variables, only income has a strong relationship with the egress mode choice. With increasing income, business travelers show a higher probability of using the car than any other mode, which is similar to the access stage. 
Trip characteristics variables have weak relationships with the egress mode choice compared to the access mode choice. For instance, the impact of egress time is not statistically significant on the egress mode choice compared to that of access time. Furthermore, with increasing line-haul time, business travelers show a high propensity for using the car rather than the bus. As in the access stage, the reason may be that business travelers who are sensitive to the total time cost and unfamiliar with the traffic conditions in the arrival city try to reduce the egress time cost by using a company car and driver at a fast travel speed if the destination is far away from stations.

In comparison to the access stage, generally, built-environment factors are much more significantly related to the egress mode choice. Perhaps obligatory business passengers who are highly constrained by space-time fixity are more influenced by the built-environment factors, especially in a fixed trip trajectory from stations to destinations in the egress stage. When business travelers arrive at HSR stations with increasing numbers of subway lines and road/street intersections within a certain area, they are less likely to choose egress by car than by subway. It is reasonable to see that increasing the number of subway line connections in the arrival HSR stations will induce higher use of subways since a transit-oriented and public transport-friendly development around the origin of a trip encourages taking public transit (Zhang, 2004; Pan et al., 2009). In addition, consistent with Zhang (2004) and Sun et al. (2017), we showed that increasing the number of road intersections around HSR station origins significantly diminishes the probability of car use for egress because of the complex and crowded driving environment.

\subsection{Leisure travel}

\subsubsection{Access stage}

Different from business travelers, socio-economic and built environment variables of leisure travelers have no impact on the access mode choice. This is in line with our expectation that the travelers' recreational activities are not highly constrained by space-time fixity compared to business travelers. Therefore, these travelers are free to choose when to access departure stations from homes for their recreational activities (Ettema \& Schwanen, 2012; Wang, 2015).

Concerning trip characteristics, compared to access time shorter than 30 minutes, access time longer than 60 minutes induces a choice for the bus over the car. As mentioned earlier, no clear causal relationship exists between access time and mode choice. A longer access time for leisure travel may be associated with an increase of bus use for a certain distance from homes to departure stations. Compared to business travelers using the subway with higher speed, this indicates that, for a given access distance, leisure travelers are more willing to accept a slower PT mode with a longer access time. This result confirms our expectation and might indicate that, compared to obligatory business travelers, discretionary leisure travelers are less sensitive to the extra time cost caused by low-speed transport for long distance intra-city travel ( Scheiner, 2010b; Farag \& Lyons, 2012; Feng, 2017). In line with this explanation, line-haul time does not have any impact on leisure travelers' access mode choice.

\subsubsection{Egress stage}

Compared to the access stage and in contrast to business journeys, socio-demographic variables are strongly related to the intra-city mode choice for leisure journeys. This means that discretionary leisure travelers are not influenced by highly fixed time-space constraints imposed by trip characteristics and built-environment factors in the egress stage since they have more choices of hotel and tourism destinations and experience more flexibility for their recreational activities in arrival cities. Age, education, and income levels influence the egress mode choice. Compared to leisure travelers younger than 30 , those older than 50 prefer friends or relatives' cars to the subway. This might be the result of aging people's declining physical condition combined with the need to carry luggage for their non-daily leisure travel. 
Also, compared to leisure travelers whose income is less than 750 euro per month, those with an income greater than 1250 euro prefer the car to PT. The results suggest that, compared to PT modes, car driving is the most convenient mode and is preferred by older and wealthier leisure travelers for their recreational activities, especially because the destination location choices of leisure travel tend to be spatially more irregular and idiosyncratic than for other kinds of travel in the arrival city (Limtanakool, Dijst, \& Schwanen, 2006; Ettema \& Schwanen, 2012). Compared to travelers with lower education, those with higher education are more likely to use the subway than the car. That is likely a result of the complicated subway signage system and multiple entries and exits in public transit stations in China (Jiang, Deng, Hu, Ding, \& Chow, 2009), which implies more difficult subway use for leisure travelers with lower education, especially in the unfamiliar egress stage.

Concerning trip characteristics, egress time variables for both business and leisure travel are not statistically related to mode choice. This means that neither type of traveler is sensitive to the egress time. Furthermore, line-haul time does not have any impact on the egress mode choice for leisure travelers. This further confirms that leisure travelers are not sensitive to the line-haul time cost compared to business travelers, which is also reflected in the access stage.

In terms of built-environment variables, increasing the diversity of land use around the arrival station lead to less use of driving, which is consistent with the previous studies that a mixed land use around the arrival areas of travelers could reduce the car use (Ewing \& Cervero, 2010; Zhang \& Zhang, 2018). It is surprising that when increasing the number of road intersections for driving, leisure travelers have a preference for car use instead of PT. This could be related to the fact that in an unfamiliar egress stage, leisure travelers could prefer to use the car which is safer and more reliable given the poor service of PT and the generally crowded bus stations.

\subsection{Elasticity analysis for the built environment variables at the micro level}

Table 6. Elasticity analysis

\begin{tabular}{|c|c|c|c|c|c|c|c|c|}
\hline \multirow[b]{2}{*}{$\begin{array}{l}\text { Built environment vari- } \\
\text { able in the access stage }\end{array}$} & \multicolumn{4}{|c|}{ Business } & \multicolumn{4}{|c|}{ Leisure } \\
\hline & Subway & Bus & Car & Taxi & Subway & Bus & Car & Taxi \\
\hline Land use entropy & -0.28 & -0.34 & 0.45 & 0.16 & -1.37 & 0.61 & -0.02 & 0.78 \\
\hline No. subway lines & 0.00 & -0.07 & 0.07 & 0.00 & -0.03 & -0.03 & 0.03 & 0.04 \\
\hline \multirow{2}{*}{$\begin{array}{l}\text { No. road/street inter- } \\
\text { sections for driving }\end{array}$} & 0.06 & 0.06 & -0.06 & -0.06 & 0.18 & -0.08 & 0.00 & -0.10 \\
\hline & \multicolumn{4}{|c|}{ Business } & \multicolumn{4}{|c|}{ Leisure } \\
\hline $\begin{array}{l}\text { Built environment vari- } \\
\text { able in the egress stage }\end{array}$ & Subway & Bus & Car & Taxi & Subway & Bus & Car & Taxi \\
\hline Land use entropy & $0.56^{* *}$ & 0.09 & -0.27 & -0.38 & 0.23 & 0.58 & -0.20 & -0.61 \\
\hline No. subway lines & $0.34^{* *}$ & -0.09 & -0.06 & -0.19 & 0.17 & -0.05 & -0.01 & -0.11 \\
\hline $\begin{array}{l}\text { No. road/street inter- } \\
\text { sections for driving }\end{array}$ & 0.12 & 0.01 & -0.03 & -0.11 & 0.02 & -0.12 & 0.02 & 0.08 \\
\hline
\end{tabular}

Notes: Only coefficients significant at 0.05 level are shown in the table. They are calculated based on Tables 4 and 5 . 
In order to have a better policy evaluation of the built environment variables, we conducted an elasticity analysis referring to (Zhang \& Zhang, 2018) for the relevant built environment information around the HSR station. Table 6 reports the probability-weighted aggregate independent elasticities with respect to built environment variables around HSR stations for all travel modes. The table lists only significant elasticities at the 0.05 level. The magnitudes of elasticities of the subway with respect to the diversity of land use and the number of subway lines appear to the only efficient way to increase the subway use in the egress stage for business travelers. This means that increasing the provision of subway lines, diversity of land use around the HSR stations could be an efficient way to promote the subway use for business travelers in the egress stage.

\section{Conclusions and discussion}

This paper starts with the observation that limited knowledge exists regarding the intra-city mode choice of HSR travelers in China. By employing data from a survey conducted by Fudan University, we have investigated the question of how socio-demographics, trip characteristics, and built-environment attributes affect the access/egress mode choice for HSR trips and how their role varies across journey purposes: business or leisure.

The analysis confirmed our hypothesis that walking and cycling are not the major access/egress modes given the relatively long distances to/from HSR stations in China. That differs from local PT (Zhao \& Li, 2017) and conventional railways (Krygsman et al., 2004) where walking and cycling have a large share in the access/egress stage, due in part to the higher density of local PT and the location of conventional railway stations in urban areas. Although the decision to plan HSR stations in the suburbs is reasonably attributable to cheaper land acquisition and a new town development strategy (Chen \& Wei, 2013), undeveloped areas around HSR stations without specific urban functions imply a rather long travel distance from travelers' home origins in the access stage or to their final activity destinations in the egress stage, which to a large extent limits the use of active transport for HSR travel. Furthermore, in line with previous findings (Scheiner, 2010a; Feng et al., 2014), the urban form at the macro level indicates that business travelers who are more sensitive to time cost tend to choose car instead of the bus to access newly built HSR stations in the suburb areas with low density. Moreover, with the increasing number of road intersections for driving around departure stations, business travelers prefer to use the bus instead of car to access stations. In the egress stage, increasing the provision of PT (especially subway lines) and the number of road intersections at the micro level will induce less car use for business travelers. For leisure travelers, built environment variables have much more impacts on the mode choice in the egress stage rather than the access stage. Increasing the diversity of land use around the arrival station lead to a less car use for leisure travelers, whereas increasing the number of intersections for driving, leisure travelers have a preference for car use which is safer and more reliable in the unfamiliar egress stage given the poor service of PT and the generally crowded bus stations.

Our results also demonstrate that age, income, and education, as traditionally important factors in mode choice (Limtanakool et al., 2006; Stronegger et al., 2010) are also important determinants for HSR travelers' access/egress mode choices. The finding reflects a typical situation in current China where richer and older HSR travelers strongly depend on car use. Gender is of less importance, which reflects a decreasing difference between men and women's travel patterns due to increasing education among women and a general emancipation of society (Feng, Dijst, Wissink, \& Prillwitz, 2017). Also, the weights associated with the two determinant variables (age and income) vary across journey purposes and intra-city stages. In particular, we found that for leisure travel (versus business travel), the explanatory power of the socio-demographic variables is much more influential in the egress than in the access stage because discretionary leisure travelers are less constrained by space-time fixity and have more des- 
tination choices and flexibility in their recreational activities in the egress stage.

Our analysis further confirms that consistent with the findings that conventional train travelers weigh access more than egress because of greater familiarity with the transport alternatives in the access than egress stage (Krygsman et al., 2004; Allard \& Moura, 2016), the access time rather than egress time is significantly related to the intra-city mode choice for both business and leisure HSR travelers. Nevertheless, trip attributes have more impacts on the intra-city mode choice for business travel than leisure travel because business travelers are more time sensitive than leisure travelers. Regarding the strong correlation between the use of public access mode and increased access time, business travelers may be enticed to shift to a faster form (subway rather than bus) in the access stage for a given access distance. However, with increasing line-haul time, only business travelers have a stronger preference for car use as their intra-city mode choice for business activities.

These conclusions have implications for the transit-oriented development (TOD) of HSR railserved cities in China with respect to social and environmental problems such as traffic congestion and air pollution caused by the monocentric and auto-oriented urban development. In the long run, regarding de facto locations of most HSR stations in the suburbs, an efficient transformation of areas around newly built HSR stations into functional urban centers is crucial for a polycentric urban form that benefits the use of PT modes for business and leisure travelers with a lot of luggage and active transport modes, especially walking for commuting travelers without a lot of luggage regarding the fact that bicycles are not largely provided around HSR stations in China. Otherwise, travelers still need to travel a long access/egress distance to undeveloped suburb areas by automobiles. With fast-increasing wealth but also a severely aging population in China, it is important to recognize that car use will continue to rise in the future without appropriate interventions from the government. Therefore, in the short run, apart from stringent and unpopular policies that prevent car ownership or usage, our research suggests that increasing the provision of subway lines, diversity of land use around the HSR stations can not only develop a highly public-transport accessible TOD but also a car-unfriendly environment with rather low travel speed for car drivers. That is an efficient solution to reduce car dependency for the major travel groups (business travelers in the egress stage) for a sustainable multimodal HSR journey.

The framework clearly has its limitations, which at the same time point to possible future research avenues. First, the current analytical framework did not include the information on origin for HSR travelers in the access stage and destination in the egress stage. Moreover, the analysis focuses on a single day trip of HSR travelers rather than seasonality pattern. This issue could be alleviated with more detailed data on that relevant information, which could provide a better understanding. Third, the analysis focused on one level of service variables (access/egress time), whereas other studies have included another level of service variables (monetary access/egress cost). Since the access/egress time could be highly correlated with the use of transport mode, the inclusion of specific monetary cost for alternative transport modes would lead to a deeper understanding of a causal relationship between the level of services variables and intra-city mode choice by structure equation model regarding a large sample size. Moreover, although the endogeneity issue is not strong enough in our study, we could not deny the potential endogeneity issue especially for a large sample size, therefore using a path analysis model (Zhang, 2016) could explicitly separate the indirect and direct impacts of socio-economic attributes and travel time for the mode choice analysis in the future. 


\section{Acknowledgement}

We would like to thank Dr. Aloys Borgers for the support on the discrete choice model. This research is sponsored by Shanghai Pujiang Program. We also thank the financial support from National Natural Science Foundation of China $(41871135,41971155)$, the Fundamental Research Funds for the Central Universities (090214380026, 090214380025) and the affiliated institutions of the first author-The Center for Modern Chinese City Studies, Future City Lab, and School of Urban and Regional Science of East China Normal University. 


\section{References}

Algers, S. (1993). Integrated structure of long-distance travel behavior models in Sweden. Transportation Research Record, 1413, 141-149.

Allard, R. F., \& Moura, F. (2016). The incorporation of passenger connectivity and intermodal considerations in intercity transport planning. Transport Reviews, 36(2), 251-277. doi.org/10.1080/0144 1647.2015.1059379

Arduin, J., \& Ni, J. (2005). French TGV network development. Japan Railway \& Transport Review, 40(March), 22-28. Retrieved from http://www.jrtr.net/jrtr40/pdf/f22_ard.pdf

Banister, D., \& Givoni, M. (2013). High-speed rail in the EU-27: Trends, time, accessibility and principles. Built Environment, 39(3), 324-338. Retrieved from http://www.ingentaconnect.com/content/ alex/benv/2013/00000039/00000003/art00002

Ben-Akiva, M. E., \& Lerman, S. R. (1985). Discrete choice analysis: Theory and application to travel demand (Vol. 9). Cambridge, MA: MIT Press.

Brons, M., Givoni, M., \& Rietveld, P. (2009). Access to railway stations and its potential in increasing rail use. Transportation Research Part A: Policy and Practice, 43(2), 136-149. doi.org/10.1016/j. tra.2008.08.002

Brons, M., \& Rietveld, P. (2009). Improving the quality of the door-to-door rail journey : A customeroriented approach. Built Environment, 35(1), 122-135.

Cervero, R. (2001). Walk-and-ride: Factors influencing pedestrian access to transit. Journal of Public Transportation, 3, 1-23.

Cervero, R., \& Duncan, M. (2003). Walking, bicycling, and urban landscapes: Evidence from the San Francisco Bay Area. American Journal of Public Health, 93(9), 1478-1483. doi.org/ 10.2105/ AJPH.93.9.1478

Cervero, R. (2002). Built environments and mode choice: Toward a normative framework. Transportation Research Part D: Transport and Environment, 7(4), 265-284. doi.org/10.1016/S13619209(01)00024-4

Chen, C.-L. (2012). Reshaping Chinese space-economy through high-speed trains: Opportunities and challenges. Journal of Transport Geography, 22, 312-316. doi.org/10.1016/j.jtrangeo.2012.01.028

Chen, C., \& Wei, B. (2013). High-speed rail and urban transformation in China: The case of Hangzhou East Rail Station. Built Environment, 39(3), 385-398. Retrieved from http://www.ingentaconnect.com/content/alex/benv/2013/00000039/00000003/art00006

Chen, L., Pel, A., Chen, X., Sparing, D., \& Hansen, I. (2012). Determinants of bicycle transfer demand at metro stations. Transportation Research Record: Journal of the Transportation Research Board, 2276(November), 131-137. doi.org/10.3141/2276-16

Commins, N., \& Nolan, A. (2011). The determinants of mode of transport to work in the Greater Dublin Area. Transport Policy, 18(1), 259-268. doi.org/10.1016/j.tranpol.2010.08.009

Crockett, J., \& Hounsell, N. (2005). Role of the travel factor convenience in rail travel and a framework for its assessment. Transport Reviews, 25(5), 535-555. doi.org/10.1080/01441640500064389

Dieleman, F. M., Dijst, M., \& Burghouwt, G. (2002). Urban form and travel behavior: Micro-level household attributes and residential context. Urban Studies, 39(3), 507-527. doi. org/10.1080/0042098022011280

Dobruszkes, F., Dehon, C., \& Givoni, M. (2014). Does European high-speed rail affect the current level of air services? An EU-wide analysis. Transportation Research Part A: Policy and Practice, 69, 461-475. doi.org/10.1016/j.tra.2014.09.004

Ettema, D., \& Schwanen, T. (2012). A relational approach to analyzing leisure travel. Journal of Transport Geography, 24, 173-181. doi.org/10.1016/j.jtrangeo.2012.01.023 
Ewing, R., \& Cervero, R. (2010). Travel and the built environment. Journal of the American Planning Association, 76(3), 265-294. doi.org/10.1080/01944361003766766

Farag, S., \& Lyons, G. (2012). To use or not to use? An empirical study of pre-trip public transport information for business and leisure trips and comparison with car travel. Transport Policy, 20, 82-92. doi.org/10.1016/j.tranpol.2011.03.007

Feng, J. (2017). The influence of built environment on travel behavior of the elderly in urban China. Transportation Research Part D, 52, 619-633. doi.org/10.1016/j.trd.2016.11.003

Feng, J., Dijst, M., Wissink, B., \& Prillwitz, J. (2014). Understanding mode choice in the Chinese context: The case of Nanjing metropolitan area. Tijdschrift Voor Economische En Sociale Geografie, 105(3), 315-330. doi.org/10.1111/tesg.12068

Feng, J., Dijst, M., Wissink, B., \& Prillwitz, J. (2017). Changing travel behavior in urban China: Evidence from Nanjing 2008-2011. Transport Policy, 53, 1-10. doi.org/10.1016/j.tranpol.2016.08.011

Givoni, M. (2006). Development and impact of the modern high-speed train: A Review. Transport Reviews, 26(5), 593-611. doi.org/10.1080/01441640600589319

Givoni, M., \& Rietveld, P. (2007). The access journey to the railway station and its role in passengers' satisfaction with rail travel. Transport Policy, 14(5), 357-365. doi.org/10.1016/j.tranpol.2007.04.004

Jiang, C. S., Deng, Y. F., Hu, C., Ding, H., \& Chow, W. K. (2009). Crowding in platform staircases of a subway station in China during rush hours. Safety Science, 47(7), 931-938. doi.org/10.1016/j. ssci.2008.10.003

Kim, S., \& Ulfarsson, G. F. (2008). Curbing automobile use for sustainable transportation: Analysis of mode choice on short home-based trips. Transportation, 35(6), 723-737. doi.org/10.1007/s11116008-9177-5

Krygsman, S., Dijst, M., \& Arentze, T. (2004). Multimodal public transport: An analysis of travel time elements and the interconnectivity ratio. Transport Policy, 11(3), 265-275. doi.org/10.1016/j.tranpol.2003.12.001

Limtanakool, N., Dijst, M., \& Schwanen, T. (2006). The influence of socioeconomic characteristics, land use and travel time considerations on mode choice for medium- and longer-distance trips. Journal of Transport Geography, 14(5), 327-341. doi.org/10.1016/j.jtrangeo.2005.06.004

Liu, S., \& Kesteloot, C. (2015). High-speed rail and rural livelihood: The Wuhan-Guangzhou Line and Qiya Village. Tijdschrift Voor Economische En Sociale Geografie, 107(4), 469-483. doi.org/10.1111/ tesg. 12169

Liu, X., \& Long, Y. (2016). Automated identification and characterization of parcels with OpenStreetMap and points of interest. Environment and Planning B: Planning and Design, 43(2), 341-360. doi. org/10.1177/0265813515604767

Martens, K. (2004). The bicycle as a feedering mode: Experiences from three European countries. Transportation Research Part D: Transport and Environment, 9(4), 281-294. doi.org/10.1016/j. $\operatorname{trd} .2004 .02 .005$

Martin, E. W., \& Shaheen, S. A. (2014). Evaluating public transit modal shift dynamics in response to bikesharing: A tale of two U.S. cities. Journal of Transport Geography, 41, 315-324. doi. org/10.1016/j.jtrangeo.2014.06.026

Martín, J. C., Román, C., García-Palomares, J. C., \& Gutiérrez, J. (2014). Spatial analysis of the competitiveness of the high-speed train and air transport: The role of access to terminals in the Madrid-Barcelona corridor. Transportation Research Part A: Policy and Practice, 69, 392-408. doi. org/10.1016/j.tra.2014.09.010

Pan, H., Shen, Q., \& Zhang, M. (2009). Influence of urban form on travel behavior in four neighborhoods of Shanghai. Urban Studies, 46(2), 275-294. doi.org/10.1177/0042098008099355 
Pels, E., Nijkamp, P., \& Rietveld, P. (2003). Access to and competition between airports: A case study for the San Francisco Bay area. Transportation Research Part A: Policy and Practice, 37(1), 71-83. doi. org/10.1016/S0965-8564(02)00007-1

Scheiner, J. (2010a). Interrelations between travel mode choice and trip distance: Trends in Germany 1976-2002. Journal of Transport Geography, 18(1), 75-84. doi.org/10.1016/j.jtrangeo.2009.01.001

Scheiner, J. (2010b). Social inequalities in travel behavior: Trip distances in the context of residential self-selection and lifestyles. Journal of Transport Geography, 18(6), 679-690. doi.org/10.1016/j.jtrangeo.2009.09.002

Schwanen, T., Dijst, M., \& Dieleman, F. M. (2001). Leisure trips of senior citizens: Determinants of modal choice. Tijdschrift Voor Economische En Sociale Geografie, 92(3), 347-360. doi.org/10.1111/14679663.00161

Shen, Y., Chai, Y., \& Kwan, M. P. (2015). Space-time fixity and flexibility of daily activities and the built environment: A case study of different types of communities in Beijing suburbs. Journal of Transport Geography, 47, 90-99. doi.org/10.1016/j.jtrangeo.2015.06.014

Stronegger, W. J., Titze, S., \& Oja, P. (2010). Perceived characteristics of the neighborhood and its association with physical activity behavior and self-rated health. Health and Place, 16(4), 736-743. doi. org/10.1016/j.healthplace.2010.03.005

Sun, B., Ermagun, A., \& Dan, B. (2017). Built environmental impacts on commuting mode choice and distance: Evidence from Shanghai. Transportation Research Part D: Transport and Environment, 52, 441-453. doi.org/10.1016/j.trd.2016.06.001

Tapiador, F. J., Burckhart, K., \& Martí-Henneberg, J. (2009). Characterizing European high speed train stations using intermodal time and entropy metrics. Transportation Research Part A: Policy and Practice, 43(2), 197-208. doi.org/10.1016/j.tra.2008.10.001

Wang, D. (2015). Place, context and activity-travel behavior: Introduction to the special section on geographies of activity-travel behavior. Journal of Transport Geography, 47, 84-89. doi.org/10.1016/j. jtrangeo.2015.08.019

Wang, J. J., Xu, J., \& He, J. (2013). Spatial impacts of high-speed railways in China: A total-travel-time approach. Environment and Planning A, 45(9), 2261-2280. doi.org/10.1068/a45289

Wen, C.-H., Wang, W.-C., \& Fu, C. (2012). Latent class nested logit model for analyzing high-speed rail access mode choice. Transportation Research Part E: Logistics and Transportation Review, 48(2), 545-554. doi.org/10.1016/j.tre.2011.09.002

Yang, M., Zhao, J., Wang, W., Liu, Z., \& Liu, Z. (2015). Metro commuters' satisfaction in multi-type access and egress transferring groups. Transportation Research Part D: Transport and Environment, 34, 179-194. doi.org/10.1016/j.trd.2014.11.004

Zhang, M. (2004). The role of land use in travel mode choice - evidence from Boston and Hong kong. Journal of the American Planning Association, 70(March 2015), 344-360. doi. org/10.1080/01944360408976383

Zhang, W. (2016). Does compact land use trigger a rise in crime and a fall in ridership? A role for crime in the land use-travel connection. Urban Studies, 53(14), 3007-3026. doi. org/10.1177/0042098015605222

Zhang, W., \& Zhang, M. (2018). Incorporating land use and pricing policies for reducing car dependence: Analytical framework and empirical evidence. Urban Studies, 55(13), 3012-3033. doi. org/10.1177/0042098017720150

Zhao, P., \& Li, S. (2017). Bicycle-metro integration in a growing city: The determinants of cycling as a transfer mode in metro station areas in Beijing. Transportation Research Part A: Policy and Practice, 99, 46-60. doi.org/10.1016/j.tra.2017.03.003 